\title{
EPIDEMIOLOGY OF SWINE TRICHINELLOSIS IN CHINA
}

\author{
WANG Z.Q.* \& CUI J.*
}

\section{Summary :}

Swine trichinellosis has been reported in 26 provinces, autonomous regions or municipalities (P/A/M) of China. The prevalence rate in swine varied from $0.12 \%$ to $34.2 \%$ in five $\mathrm{P} / \mathrm{A} / \mathrm{M}$, from $0.01 \%$ to $0.0001 \%$ in other $\mathrm{P} / \mathrm{A} / \mathrm{M}$. The seroepidemiological survey of swine trichinellosis was carried out by ELISA in seven $P / A / M$, the seroprevalence varied from $0.09 \%$ to $29.63 \%$. The prevalence of Trichinella infection in pork sold at the market was from $0.29 \%$ to $5.6 \%$ in four provinces. The transmission of trichinellosis by garbage is the main features of epidemiology of swine trichinellosis in China. Rat is an important reservoir in the domestic cycle of trichinellosis. The prevalence rates of $T$. spiralis infection in rats were from $1.98 \%$ to $15.06 \%$ in six provinces or autonomous regions. The treatmentprophylaxis with forage contained albendazole has been applied to the control of swine trichinellosis in Nanyang area of Henan province, the prevalence of swine trichinellosis had decreased from $32.2 \%$ before prophylaxis to $0.12 \%$ after prophylaxis.

KEY WORDS : trichinellosis, Trichinella spiralis, epidemiology, swine, rat, China.

T frichinellosis is still a serious zoonosis which is widely distributed in China. Pork is the main source of Trichinella infection for humans in China (Wang et al., 1998). Moreover, the data on the nationwide prevalence of swine trichinellosis were rare in China. Hence, the aim of our work is a review of swine trichinellosis in China. It is based on the publications on epidemiology of swine trichinellosis in China. The materials were systematized and analyzed respectively for trichinellosis of swine and rat in this paper.

\section{EPIDEMIOLOGICAL DATA}

\section{PREVALENCE OF SWINE TRICHINELLOSIS}

wine trichinellosis was reported in $26 \mathrm{P} / \mathrm{A} / \mathrm{M}$ of China. Five provinces belonged to the high ende$\checkmark \mathrm{mic}$ areas where the prevalence was more than $0.1 \%$ (Table I). Nine $\mathrm{P} / \mathrm{A} / \mathrm{M}$ belonged to the low endemic areas, where the prevalence varied from $0.0001 \%$ to $0.0897 \%$ (Table II). The prevalence of swine trichinellosis detected in abattoirs of the other eight $\mathrm{P} / \mathrm{A} / \mathrm{M}$ in 1982 was $0.007 \%$ in Gansu, $0.006 \%$ in Ningxia, $0.001 \%$ in Xinjiang, $0.001 \%$ in Guizhou, $0.003 \%$ in Guangxi, $0.04 \%$ in Shanxi, $0.026 \%$ in NeiMongol, and $0.002 \%$ in Jiangsu (Zhu, 1993). In addition, swine trichinellosis was recorded in Zhejiang, Fujian and Xizang.

\section{SEROPREVALENCE OF SWINE TRICHINELLOSIS}

The seroepidemiological survey of swine trichinellosis was carried out by indirect ELISA in seven provinces or municipalities of China (Table III). The ELISA method was performed as described before (Li et al., 1991). The mean O.D. value of negative sera from 135 healthy pigs was 0.12 . The positive cutoff was determined to be four times of the mean of negative sera. The seroprevalence was from $0.09 \%$ to $19.89 \%$.

\begin{tabular}{|c|c|c|c|c|c|}
\hline Location & Year & No. examined & No. infected & $\%$ infected & Reference \\
\hline Liaoning & 1980 & 685418 & 232 & 0.34 & Li, 1980 \\
\hline Heilongjiang & 1998 & 1878874 & 2274 & 0.12 & Jia et al., 1998 \\
\hline \multirow[t]{2}{*}{ Hubei } & 1987 & 1539768 & 33550 & 2.18 & Xu \& Cao, 1987 \\
\hline & 1997 & 290294 & 19637 & 6.76 & Xu \& Cao, 1997 \\
\hline Henan & 1986 & 3630 & 1243 & 34.20 & Wu et al., 1986 \\
\hline \multirow[t]{2}{*}{ Yunnan } & 1991 & 15515 & 157 & 1.00 & Yang, 1991 \\
\hline & 1999 & 4314000 & 1329 & 0.31 & Qian et al., 1999 \\
\hline
\end{tabular}

Table I. - Prevalence of trichinellosis in pigs slaughtered in abattoirs by five microscopic examination in five provinces.

* Department of Parasitology, Henan Medical University, Zhengzhou 450052, China.

Tel. : (86)371-6975190 - e-mail : wangzhongq@371.net 


\begin{tabular}{lccccc}
\hline Location & Year & No. examined & No. infected & \% infected & Reference \\
\hline Jilin & 1982 & 1644700 & 24 & 0.0015 & Zhu,1993 \\
Beijing & 1982 & 2322300 & 25 & 0.0011 & Zhu,1993 \\
Tianjing & 1982 & 1270200 & 14 & 0.0011 & Zhu, 1993 \\
Shangdong & 1993 & 69460962 & 7116 & 0.0102 & Lu et al., 1993 \\
Shaanxi & 1982 & 251340 & 11 & 0.0044 & Zhu, 1993 \\
Anhui & 1982 & 2406200 & 198 & 0.0082 & Zhu, 1993 \\
Hunan & 1982 & 2782700 & 3 & 0.0001 & Zhu, 1993 \\
Sichun & 1999 & 1568900 & 2 & 0.0897 & Jia \& Yin, 1999 \\
Guangdong & 1982 & 1587 & 20001 & Zhu, 1993 \\
\hline
\end{tabular}

Table II. - Prevalence of trichinellosis with low level of infestation in nine provinces by microscopic examination in pigs slaughtered in abattoirs.

\begin{tabular}{|c|c|c|c|c|c|}
\hline Location & Year & No. examined & No. infected & $\%$ infected & Reference \\
\hline Beijing & 1991 & 1062 & 1 & 0.09 & Ji et al., 1991 \\
\hline Liaoning & 1991 & 623 & 14 & 2.25 & Wang et al., 1991 \\
\hline Heilongjiang & 1998 & 365 & 38 & 10.41 & Song et al., 1998 \\
\hline Henan & 1989 & 47031 & 8927 & 19.89 & Zhang et al., 1989 \\
\hline Hubei & 1987 & 1459 & 24 & 1.64 & Tong \& Li, 1987 \\
\hline Hunan & 1989 & 550 & 94 & 17.1 & Fan \& Liu, 1989 \\
\hline Yunnan & 1999 & 320 & 20 & 8.70 & Qian et al., 1999 \\
\hline
\end{tabular}

Table III. - Seroprevalence of swine trichinellosis in China by indirect ELISA.

\section{PREVALENCE OF TRICHINELLA IN PORK SOLD AT THE MARKET}

The custom of unauthorized, domestic slaughtering without veterinary controls has been handed down from generation to generation in China, especially in rural areas. Thus, the prevalence of Trichinella infection in pork sold at the market in China was high. From 1985 to 1998, prevalence of Trichinella infection in pork sold at the market was investigated by direct microscopic examination in several provinces of China.
The results showed that the prevalence of Trichinella in pork varied from $0.29 \%$ to $5.6 \%$ (Table IV).

\section{PREVALENCE OF RAT TRICHINELLOSIS}

Since the prevalence of swine trichinellosis was considered to be well correlated to the prevalence of rat trichinellosis, the epidemiological survey of rat trichinellosis was also carried out by direct microscopic examination and artificial digestion method in six provinces. The prevalence of $T$. spiralis infection in rats varied from $1.98 \%$ to $15.06 \%$ (Table V).

\begin{tabular}{lccccc}
\hline Location & Year & No. examined & No. infected & \% infected & Reference \\
\hline Yunnan & 1985 & 254 & 2 & 0.80 & Zhang, 1985 \\
Henan & 1997 & 75821 & 324 & 4.27 & Wang et al., 1997 \\
Gangsu & 1997 & 684 & 2 & 0.29 & Zang et al., 1997 \\
Hubei & 1998 & 12374 & 693 & 5.60 & Ye et al., 1998 \\
\hline
\end{tabular}

Table IV. - Prevalence of Trichinella infection in pork sold at the market in China.

\begin{tabular}{lccccc}
\hline Location & Year & No. examined & No. infected & \% infected & Reference \\
\hline Fujian & 1939 & 136 & 3 & 2.21 & Tang, 1939 \\
Henan & 1986 & 347 & 18 & 5.19 Wu et al. 1986 & Yi et al., 1987 \\
Hubei & 1987 & 332 & 50 & 15.06 e & Ye et al., 1998 \\
& 1998 & 2667 & 279 & 10.46 & Yang, 1985 \\
Yunnan & 1985 & 130 & 27 & 1.08 & Yang, 1991 \\
Xizang & 1991 & 362 & 2 & 4.44 & Zheng et al., 1975 \\
Guangxi & 1975 & 15 & 1 & 5.26 & Gan et al., 1995 \\
\hline
\end{tabular}

Table V. - Prevalence of rat trichinellosis in China. 


\section{CONTROL OF SWINE TRICHINELLOSIS}

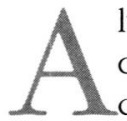
lthough the policy that pigs are slaughtered and quarantined for trichinellosis in abattoirs was carried out in China since 1996, it is difficult to examine all pigs for diagnosis of trichinellosis, especially in rural areas with home slaughtering. Therefore, treatment-prophylaxis was applied to the control of swine trichinellosis in some endemic areas. The pigs were fed with forage containing albendazole for 34 months, the prevalence of swine trichinellosis decreased from $32.2 \%$ before prophylaxis to $0.12 \%$ after prophylaxis in Nanyang area of Henan province.

\section{TRANSMISSION OF SWINE TRICHINELLOSIS}

$\circlearrowleft$ ince the $T$. spiralis larvae were found in pork for the first time in 1881 in China, it has been considered that the domestic pig is the most important element of the domestic cycle of trichinellosis. Swine trichinellosis in China was mainly transmitted by garbage (ie. feeding pigs with uncooked pork scraps). Although there are some large pig farms, most of pigs are mainly raised by individual farmer in China. Many Chinese farmers have the habit of feeding pigs with raw garbage or pasturing pigs outdoors, so pig can easily eat the garbage which contains the living Trichinella larvae. A survey showed that all of 10,252 pigs raised in Menglou area of Hubei province were freely foraged without piggery (Yi et al., 1987).

There is no specific domestic Trichinella strain capable to infect domestic pigs only or a Trichinella strain adapted to wild animals only. This nematode can easily be transferred from domestic pigs to wild animals. Rat is an important reservoir in the domestic cycle of trichinellosis in China. The prevalence of rat trichinellosis was also high in some areas of China where the prevalence in swine was high. Thus, the high prevalence of swine trichinellosis is to be attributed to the possible ingestion of rats, which are often parasitized by $T$. spiralis (Yi et al., 1987). Hence, in order to eradicate swine trichinellosis, the traditional pig-rearing mode should be changed, all pigs should be raised in piggery and all garbage must be boiled for 30 minutes before being fed to pigs so that the Trichinella larvae contained in the garbage can be completely killed. In addition, the possibility of the transfer of infection from rats to pigs must be considered for the control of swine trichinellosis.

\section{REFERENCES}

FAN W. \& LIU D. Seroepidemiological survey of pig trichinosis in Changsha, Lixi and jishou of Hunan province. Journal of Hunan Medical University, 1989, 14, 47-49.
Ji Y., CaO Y.J., Lin J.Y., Su S.G., Li S. \& Gan S.B. Serological investigation of swine infections with some parasites in Beijing area, in : Proceedings of the $2^{\text {th }}$ National Conference of Yong Parasitologists. Chinese Society of Parasitology (eds). Xian, 1991, 114-115.

JiA L.Z., GuO X.J., Zhang H.P. \& XIAO J.Y. A survey of common diseases of pigs slaughtered in abattoirs of Harbin city of China. Chinese Journal of Meat Hygiene, 1998, (1), 5-8.

JIA R.R. \& YIN Z.Q. A survey of swine trichinellosis in Xichang city of Sichun province. Chinese Journal of Meat Hygiene, 1999, (5), 5-6

LI D.Y. A survey of Trichinella infection in dogs, cats and pigs in Lioning province. Journal of China Medical University, 1980, 2,1-2.

LI S.T., Wang X.Z., QIu Z.L., Wei J.B. \& Zhang X.F. Development and application of rapid ELISA kit for diagnosis of zoonotic trichinosis. Chinese Journal of Zoonoses, 1991, 7, 23-25.

Lu Y., GaO C.L., GAO F.L. \& Cui Z.H. Statistical analysis of swine trichinellosis and cysticercosis in Shangdong province. Chinese Journal of Parasitic Disease Control, 1993 , 6, 157-158.

MENG D.G. \& WANG M. An outbreak of trichinosis. Chinese Journal of Preventive Medicine, 1995, 19, 305.

Qian J.S., Peng Y.K., Zhang L.L., Yang Z.W., Wang H.Z., Li Y., Li S.S. \& LiANG L.X. A seroepidemiological survey of swine trichinellosis in two endemic areas of Yunnan. Chinese Journal of Zoonoses,1999, 15, 230-231.

Song M.X., Lu Y.X., Li S.S., Zhou Y.C., Lin M.L., Jiang S.Z., Hu T.Y., Zhang J.Q. \& LOU G.P. Seroepidemiological survey of swine trichinellosis in Mudanjiang city. Chinese Journal of Meat Hygiene, 1998, (9), 6-7.

TANG C.C. Trichinella infection in rats in Fukien. Chinese Medical Journal, 1939, 55, 537-541.

TONG S.D. \& Li L.S. Seroepidemiological survey of swine trichinellosis in Hubei province. Chinese Journal of Zoonoses, 1987, 3, 45.

WANG H., ChEn X.Q. \& GU Y. Serological survey of human and swine trichinosis in Shengyang. In : Proceedings of the $2^{\text {th }}$ National Conference of Yong Parasitologists. Chinese Society of Parasitology (eds). Xian, China, 1991, 74.

Wang P.R., Zhang D., Yang H.C., Dong G.F. \& Cheng X.S. Investigation on pork of Trichinella infection in Henan Province. Chinese Journal of Zoonoses, 1997, 13, 71-72.

Wang Z.Q., Cui J., Wu F., MaO F.R. \& Jin X.X. Epidemiological, clinical and serological studies on trichinellosis in Henan province, China. Acta Tropical, 1998, 71, 255-268.

Wu A.H., CAI C.H. \& YuAN Y.X. An investigation of trichinosis in Denxian county, Henan province. Journal of Parasitology \& Parasitic Diseases, 1986, 4, 66.

XU Z.M. \& CAO Z.X. Trichinosis and cysticercosis of pigs in Xiangfan city during 1972-1985. Chinese Journal of Zoonoses, 1987, 3, 43.

XU Z.M. \& CAO Z.X. A survey of trichinosis and cysticercosis of pigs in Xiangfan city. Chinese Journal of Parasitology E Parasitic Diseases, 1997, 15, 55. 
YANG G.L. A survey of six outbreaks of trichinollosis in Reili county of Yunnan province. Chinese Journal of Preventive Medicine, 1985, 19, 254.

YANG H.M. Studies on epidemiology and control of trichinosis in Yunnan province. Chinese Journal of Parasito$\log y$ \& Parasitic Diseases, 1991, 9 (Suppl), 79-82.

Ye J.J., Zhang S.Q., Chen S.L., Sheng X.D. \& Pei S.J. Investigation on infection of the human Trichinella spiralis in Hubei province. Chinese Journal of Parasitic Disease Control, 1998, 11, 111-113.

YI W.M., YANG J.R. \& JIN J.A. A survey on Trichinella spiralis infection of hogs and rats with special reference to their relationship. Chinese Journal of Preventive Medicine, 1987, 21, 139.

Zang R.X., LIU X.F., Zhang X.Y., ZHaO W.P. \& Hou S.L. Investigation on Trichinella spiralis infection of porks sold at markets in Lanzhou city of Gansu province. Chinese Journal of Meat Hygiene, 1997, (3), 17.

ZHANG G.H. Investigation on Trichinella spiralis infection of meats sold at markets in Kunming. Journal of Parasito$\log y$ \& Parasitic Diseases, 1985, 3, 275.

Zhang S.W., Wu Y.Y., An Z.B., Chen J.S. \& Wang Y. Detection of swine trichinellosis by using ELISA. Chinese Journal of Veterinary Science and Technology, 1989, 6, 31-33.

ZHU X.Q. Epidemiology of trichinellosis in animals in China, in: Trichinellosis. Zhu X.Q., Gong G.X., Xue F.H. \& Gui Y.Z.(eds), Henan Science and Technology, Zhengzhou, China, 1993, 113-119. 